\title{
What Concerns Workers with Low Back Pain? Findings of a Qualitative Study of Patients Referred for Rehabilitation
}

\author{
Carol Coole • Avril Drummond • Paul J. Watson • \\ Kathryn Radford
}

Published online: 7 April 2010

(c) The Author(s) 2010. This article is published with open access at Springerlink.com

\begin{abstract}
Introduction Health and workplace strategies to address work loss and sickness absence due to low back pain are urgently required. A better understanding of the experiences of those struggling to stay at work with back pain may help clinicians and employers with their treatment and management approaches. Methods A qualitative approach using thematic analysis was used. Individual semi-structured interviews were conducted with a convenience sample of 25 low back pain patients who had been referred for multidisciplinary back pain rehabilitation. All were in employment and concerned about their ability to work due to low back pain. Initial codes were identified and refined through constant comparison of the transcribed interview scripts as data collection proceeded. Themes were finally identified and analysed by repeated study of the scripts and discussion with the research team. Findings Five main themes were identified: justifying
\end{abstract}

C. Coole $\cdot$ A. Drummond

Division of Rehabilitation and Ageing, School of Community Health Sciences, Faculty of Medicine, University of Nottingham, Nottingham, UK

A. Drummond

e-mail: avril.drummond@ nottingham.ac.uk

P. J. Watson

Department of Health Sciences, Academic Unit,

University of Leicester, Leicester, UK

e-mail: pjw25@leicester.ac.uk

\section{K. Radford}

Clinical Practice Research Unit, Faculty of Health,

University of Central Lancashire, Preston, UK

e-mail: kradford@uclan.ac.uk

C. Coole $(\bowtie)$

Division of Rehabilitation and Ageing, B Floor, Medical School, Queens Medical Centre, Nottingham NG7 2UH, UK

e-mail: carolyn.coole@nottingham.ac.uk back pain at work; concern about future ability to retain work; coping with flare-ups; reluctance to use medication; concern about sickness records. Conclusions In this study, workers with low back pain remained uncertain of how best to manage their condition in the workplace despite previous healthcare interventions and they were also concerned about the impact back pain might have on their job security and future work capacity. They were concerned about how back pain was viewed by their employers and co-workers and felt the need to justify their condition with a medical diagnosis and evidence. Clinicians and employers may need to address these issues in order to enable people to continue to work more confidently with back pain.

Keywords Back pain - Work - Work retention . Employed · Concerns · Qualitative research

\section{Introduction}

Back pain is a common health condition which can affect people's ability to work. It is often recurrent, but need not lead to work disability; those affected can succeed in returning to, and/or retaining employment [1-3]. However, success relies on appropriate management by both employer and employee, and the healthcare that the employee may access. The current evidence-based approach to the occupational management of low back pain is that people remain at work with temporary adjustments if required, or take minimal sick leave, returning to usual hours and duties as soon as possible. This can be combined with medical care and access to physical therapies [4]. For those whose back pain has become a 'chronic' or persisting problem, multidisciplinary biopsychosocial rehabilitation with an occupational focus is recommended $[5,6]$. 
The UK government is committed to improving the health of the working-age population, supporting those with health conditions to remain in work, and reducing the economic costs of working-age ill-health [7]. This will require healthcare to become more work-focused, and workplaces to promote the well-being of their workers. Low back pain is a main cause of sickness absence in the UK [8] where an estimated 3.5 million working days were lost in 2008/2009 through musculoskeletal disorders mainly affecting the back [9]. Effective health and workplace strategies to address work loss and sickness absence due to back pain are therefore urgently required.

Much of the data on factors affecting the work ability of people with low back pain have been collected through quantitative research using questionnaires and sickness absence to measure outcomes [5]. Most of the research to date has been conducted in North America and Scandinavia and driven by insurance-based schemes. Qualitative research conducted on patients' experiences of work and low back pain has been carried out with either those returning to work after occupational injury [10-13] or those who have been work-disabled for several years [14, 15]. However, this tells us little about the experiences of those who continue to work with back pain. A greater understanding of this might enable clinicians and employers to address the needs of this client group more appropriately.

Thus the aim of this study was to explore the individual experiences and perceptions of patients awaiting rehabilitation who were concerned about their ability to work because of persisting, or recurrent, low back pain.

\section{Method}

\section{Research Design}

A qualitative approach using thematic analysis was used [16] within an essentialist methodology, reporting the experiences, meanings and reality of the participants. A partly theoretical or deductive perspective was taken in that a literature review informed the interview framework; it is suggested that this method can enable the researcher to be more sensitive to subtleties within the data [17]. However, the framework was adaptable to enable the researchers to explore other unanticipated significant themes or patterns.

Data was collected through individual semi-structured interviews with a convenience sample of low back pain patients who had been offered multidisciplinary rehabilitation. The main objective of the interview was to facilitate each participant in reporting their individual experience of working with low back pain prior to attending a back pain rehabilitation programme.
Ethical approval was granted by the Nottingham 1 Research Ethics Committee, and the Research and Development Departments of the Primary Care Trusts concerned.

\section{Participants}

Participants were recruited over an 8 week period by clinicians from a multidisciplinary back pain rehabilitation team during routine initial assessment, following referral by the patient's GP or other healthcare professional. The eligibility criteria were the participant was (1) employed (2) concerned about their ability to work due to low back pain (3) fluent in English and (4) had been offered a programme of rehabilitation.

\section{Data Collection/procedure/interviews}

Eligible patients were given verbal and written information about the interviews by clinicians at their initial assessment. The researcher then contacted each potential participant by telephone to gain verbal consent to the interview, and, if given, to arrange a convenient time and location before the back pain rehabilitation programme started. The interviews took place during July and August 2008, either at the participant's home, workplace, or at the office base of the rehabilitation team. Interviews lasted approximately $45 \mathrm{~min}$ and were digitally recorded. Written consent was obtained at the interview.

A list of topic areas using open questions and prompts were developed through a review of the literature, by discussion with two user representatives, and between the authors. Topics included: experience of working with back pain; help received in managing symptoms at work; expectations of rehabilitation regarding work. The list was prepared as a guide for the interviews to ensure that the same topics were covered, but which still allowed participants to add further individual experiences and observations; amendments and additions to the guide were made in response to new topics arising as the interviews progressed.

\section{Data Analysis}

All of the interviews were conducted and recorded by the interviewer and transcribed verbatim. To manage the data systematically, NVivo8, (QSR International Pty Ltd) a qualitative software package was used to help code each transcript; initial codes were refined following constant comparison of the interview scripts. The researcher kept a reflective log of additional information related to theoretical and practical issues arising from the interviews. As the data collection proceeded, themes were identified and analysed by repeated study of the scripts and discussion 
with the research team. When all the data had been collected and coded, two of the researchers (CC and PJW) then reviewed and agreed the final themes.

\section{Findings}

Forty-seven patients met the inclusion criteria. Of these, thirty-five agreed to a follow-up call from the researcher. Of these thirty-five, seven declined to be interviewed and three agreed to participate but did not attend the interview. Thus a total of twenty-five patients participated in the study. They represented both private and public sector; professional, skilled, semi-skilled and unskilled work. The majority $(n=20)$ worked for large employers. Six had never taken sick leave for back pain. Six were off sick due to back pain at the time of interview, four of these for less than 6 months. Two participants reported that their back pain followed an accident at work; both were on modified duties. The mean age of the participants was 44.7 years, and mean history of back pain 6.8 years. A summary of demographic details are shown in Table 1.

All of the participants expressed a positive attitude towards working; even those who were in lengthy disputes with their employers reported that they liked their actual jobs. A total of five themes were identified from the data that were related to the participants' concerns about working with back pain.

\section{Justifying Back Pain at Work}

The majority of participants felt cautious about disclosing the fact that they had back pain (e.g. asking for help, applying for different work, taking sick leave) because they might be labelled a fraud, or as disabled which they perceived could prevent them from working or which might make them seem unreliable due to having a health problem:

Yeh because people think that you're swinging the lead as they say, because it's not a visible thing, so many people use it as an excuse, because it's an easy excuse, that whenever a person says they've got a back problem it's 'yeh, yeh, yeh'. I remember at my sickness interview - you can see the disbelief in the manager's eyes, and I'm thinking OK well..... (male aged 37)

Therefore if people did have to disclose their back pain, they were keen to justify their symptoms by using what they felt would be a more acceptable explanation. Those who were in dispute with their employers, or considering a compensation claim for a work-related injury were particularly keen to seek investigations in order to receive a diagnosis/attribute a cause:
Table 1 Demographic details of participants $(n=25)$

\begin{tabular}{|c|c|}
\hline \multicolumn{2}{|l|}{ Sex } \\
\hline Male & 12 \\
\hline Female & 13 \\
\hline \multicolumn{2}{|l|}{ Age } \\
\hline Mean age & 44.7 \\
\hline Age range & $22-58$ \\
\hline \multicolumn{2}{|l|}{ Education level } \\
\hline Secondary school & 9 \\
\hline GCSE & 4 \\
\hline Further education & 8 \\
\hline Higher education & 4 \\
\hline \multicolumn{2}{|l|}{ Length of back pain history } \\
\hline Mean & 6.8 years \\
\hline Range & 3 months -35 years \\
\hline \multicolumn{2}{|c|}{ Treatment for back pain from clinicians other than GP } \\
\hline Yes & 19 \\
\hline No & 6 \\
\hline \multicolumn{2}{|l|}{ Work status at interview } \\
\hline At work & 19 \\
\hline Off sick & 6 \\
\hline \multicolumn{2}{|l|}{ Employer profile } \\
\hline Large (>250 employees) & 20 \\
\hline Medium ( $>50,<250$ employees) & 0 \\
\hline Small ( $<50$ employees) & 3 \\
\hline Self-employed & 1 \\
\hline Self-employed/agency & 1 \\
\hline \multicolumn{2}{|l|}{ Sick leave ever for back pain } \\
\hline Yes & 19 \\
\hline No & 6 \\
\hline \multicolumn{2}{|l|}{ Sick leave in previous 6 months } \\
\hline None & 11 \\
\hline 1-7 days & 3 \\
\hline $1-6$ weeks & 5 \\
\hline $6-12$ weeks & 3 \\
\hline$>18$ weeks & 3 \\
\hline
\end{tabular}

I went to Occupational Health - I had nothing to hide - I took all my records - I'm not making anything up - I had evidence, I had an MRI scan - I'm not lying. (female age 30)

Some felt that their condition should therefore be better validated by a specific diagnosis on the sickness certificate:

I mean that first sick note said back pain. Well that can mean back pain - a bit of backache - do you know what I mean? And actually, on the one that he wrote - because I'm going to talk to him about it - on the one he wrote - because to me it's really important that my work know what's going off. And like, even though I'd explained to my boss that I've got a 
bulging disc, and I told her how painful it is, and my position, on that 6 week paper, he put lumbago - well that's backache isn't it?! And I weren't happy with that. (female age 38)

For the participants in this study, the uncertainty of what was wrong with their back was a common theme, together with the desire to attribute a cause. Some had received diagnoses by healthcare professionals, and several had had scans and X-rays. Others had developed their own explanations, usually involving some kind of structural change to the spine, in an attempt to explain their symptoms. The terms 'wear and tear', 'degeneration' and 'arthritis' were used by several of the interviewees. Participants commonly linked their condition to a history of heavy physical work or attributed it to a specific traumatic event in the past and several thought that age was a contributory factor:

And I do sometimes think - because I've worked for 15 years with old people, and I do sometimes think, because things do change - and now we know it's wrong to lift like that - and actually they don't even let you lift any more, it's called assisted, so they double up, and I do sometimes think is that - because my GP said that there was significant wear and tear at the base of my spine and I do sometimes think has that had anything to do with it because at the end of the day I'm only 37. (female)

See I'm not sure whether the pain that I've got is aggravated by the job I do - or if I'm getting old. And sometimes, as I'm doing my work it goes off anyway. So I'm not sure. (male aged 53)

\section{Concern About Future Ability to Retain Work}

For many of the participants in this study, being unsure what was wrong with their backs led to uncertainty about their future working capacity. These uncertainties centred on the possibility of having to retire earlier than planned, not being able to enjoy their retirement if they carried on working, having to stop work, experiencing increased pain at work, having to retrain or not be able to continue their chosen career:

I can retire in a year's time, I'm 60 in a year's time, but I wasn't even thinking of that - because with the friends I work with, I've worked with them for years, some of them are 62, 63. You know, just doing $16 \mathrm{~h}$, a bit less, and I thought well I could do that until I've had enough. Never thought of all this happening. (female age 58)

What worries me about it? Well if me back's aching for - say - 18 month, and I'm 44 this year, I've still got another - 21 years left at work, if it carries on. And obviously, the concern is, if me back's killing me now, what am I going to be like in later times. And am I still going to be earning the money to pay the mortgage? That's the only concern about working in general really. Cos everything else I just slow down (male age 43)

I do love this job and I love all the residents, and they say 'you're not going to leave are you? And I say 'Oh no, you're not going to get rid of me! But I do worry, will I still be able to do this when I'm sixty? Because I know some people at sixty, they're fit as a fiddle. But the only thing I worry about is will my back be able to take it? (female age 50)

For many therefore, the expectation was that their working capacity would be likely to decrease over time. If patients believe that their pain is associated with 'wear and tear' or 'arthritis' or 'degeneration', they may also believe that their health condition will naturally worsen with age. Age-related explanations may be used by clinicians with the intention of reassuring patients as to the benign nature of their condition, but may be interpreted by patients as implying progressive deterioration [18].

\section{Difficulty in Coping with Flare-ups}

There was uncertainty relating to the unpredictable and variable nature of the pain, which seemed to be outside of the participants' control:

I'd lost confidence in my back because it can go at any time - at one time it went, last October when I was dancing. It can just go any time, doing anything, and when you are walking around, or climbing in or out of a car, you've always got in the back of your mind - because it's flared up doing different things, you're thinking - Oh is it going to flare up again? (male age 37 )

Recurrent flare-ups can disrupt the consistency of ability to work as this self-employed participant describes:

I'm at the point now when I start working - any particular work - that night I'm not going to be able to sleep - my back is in pain again. It will take me two days to recover. I'm lucky if I can do about two or three days a week now. (male age 43)

This businessman describes the intense, immobilising quality of the pain and its effect on his ability to get to work:

"You said that you were concerned about your work ability......" 
Yes, because as I say, when you get these attacks, and when you're having to crawl on all fours to get to the toilet, and it's took you 15-20 min to get out of bed, that to me is pretty serious. (male age 56)

There was concern about whether employers would continue to tolerate recurrent episodes:

'Yeh I said to my GP 'look they're getting fed up at work you know, when this happens' (a flare-up), the pressure that is put on you when you do take time off is crazy really' (technician age 56)

Other studies have reported on the fact that chronic pain fluctuates, rather than being constant [14, 19], and is outside of the control of the patient. For some patients, the inconsistency of severely painful episodes which are followed by periods when the pain is hardly noticeable may lead the patient to question the validity of any medical explanations they have received, or doubt the validity of their own subjective feelings of pain [20]. Unless the normality of fluctuating symptoms is explained by clinicians to patients and their employers, patients may not feel comfortable in asking for help.

\section{Reluctance to Use Medication}

Current guidelines [21-23] support the use of medication (e.g. paracetamol, NSAIDs, weak opioids) in promoting the management of low back pain in terms of symptoms control and maintaining activity, including work, but the participants in this study were generally dismissive of medication as a treatment:

Just - well you go to the doctors and all you get to do is take painkillers and stuff like that (male age 56)

Many were uncertain about the side-effects, effectiveness or the safety of the medication they had been offered to help control their pain, and the impact on their work:

I'm not a great lover of painkillers because I know from other peoples' experiences you start on one painkiller, and then you have to go higher and higher and higher - the dosage gets higher and I'd rather work through the pain rather than keep relying on painkillers (female age 57)

....so I had to stop taking the medication so I could go to work.... (female age 44)

..he's (GP) given me some other ones now, but we read the side-effects, and it's 'don't drive, don't operate heavy machinery, don't do this, don't do that - and it's like I can't take it, because I drive to work, operate a fork-lift....so I can't take them can I? (male age 43)
Analgesia is one of the few treatment interventions for back pain available directly from the GP (and to some extent) pharmacists. The participants in this study saw that prescribing medication was a main role of the GP, yet many questioned the extent of its value.

\section{Concern About Sickness Records}

For many participants there was uncertainty about the extent to which having time off work with their back pain was, or might be viewed, negatively, depending on their experience of their employer's absence management policy and procedures. Employers may not always find the right balance between supporting employees with health problems, and taking action against those who try to take advantage of occupational sick pay [8]. Worries were expressed about disciplinary measures being taken which might affect their job security, or attempts to find alternative work:

I am worried - because I don't have a lot of time off, and I know people that have been off for a long time, even gone into hospital and had an operation, and they're cautioned going back - and I don't really want that on my record. D'you know what I mean? So that worries me a bit, but there's nothing I can do, I'll just have to deal with that when and if it happens..... because if it did come that I was ever made redundant, or I wanted to change my job companies look at that (sickness record), and it does make you reluctant to have time off sick, because you might not get the job because of your sick record, and the problem is with back pain is - nobody can see it, that you're not unwell. (female age 37 )

This office worker describes the effect of company bonus schemes on her decision whether or not to take time off:

I suppose in some ways I just resign myself to the fact and think, well I'll just keep coming to work, and if I have to take time off, eventually, then I do. I mean the company's got this thing where they're trying to drop the number of absentees there are, and if by the end of the year those figures come down, we get a bonus. It's a bit like dangling a carrot to us I suppose. (female age 46)

For many, back pain is a recurrent problem, with acute flare-ups which generally settle quickly. However, two participants described how their employers would only 'take back pain seriously' if a person had a sickness certificate for back pain-taking occasional days off due to back pain would not be seen as legitimate reason for absence: 
.....because now I've been off 3 months solid. Now if I'd taken the odd day off - they wouldn't look at it that way - they'd say 'you can't be off for a bad back like this, having a day off then 'I feel better' so I'll go back to work and then next week...off again - they're very funny that way..... although this is another reason why my GP's kept me off work - because they'll look at my record and say 'Oh she's had a day off here, and a day off there, supposed to have a bad back' (female age 57)

....and because I had no pattern of being off with back pain, they wouldn't extend my trigger points ${ }^{1}$ even though Occupational Health recommended it. Because there's no pattern they wouldn't say you can have ' $x$ ' more days off because of your back problem. So I thought well I haven't done myself any favours by coming to work in pain. I literally don't come into work unless I can't walk. So it's a 'damned if I do and damned if I don't' if you see what I mean. (female age 44)

To avoid having to take sick leave, several participants had chosen to use/considered using annual leave instead. One 35-year-old staff nurse described how she had used her annual leave in the past instead of absenting with back pain. When she had taken sick leave, her symptoms were easier to manage, but she then felt that she could not be seen going out of her house as others might doubt the authenticity of her pain.

\section{Discussion}

This study aimed to explore the individual experiences and perceptions of patients, prior to attending a rehabilitation programme, who were concerned about their ability to work due to low back pain. The participants demonstrated that underlying and unresolved issues about their health condition were contributing to their concerns about their ability to work. This was despite most of the participants having seen clinical specialists as well as their GP. Participants wanted to be able to explain their symptoms, but attaching a diagnosis to low back pain is difficult; most is due to 'non-specific' pathology [25]. Recurrences are common and normally self-limiting, but approximately $5 \%$ of those with an acute episode will develop chronic low back pain and related disability. Guidelines recommend

\footnotetext{
${ }^{1}$ A trigger point is a specified amount of sickness absence at which an employees' sickness record may be examined to decide what action, if any, may be necessary. If an employee is disabled (according to The Disability Discrimination Act [24] and is expected (following medical advice) to have a higher level of absence than an employee without a disability, the trigger point for the employee may be adjusted to allow for this.
}

that clinicians should primarily aim to reassure patients as to the benign nature of non-specific low back pain [21-23], but recent research has shown that explanations used by GPs and physiotherapists remain biomechanical in nature [26] and that many patients become frustrated by the lack of a meaningful diagnosis [19, 20]. Inappropriate or mistaken beliefs about the cause of back pain have been identified as an obstacle to recovery [27].

Most participants in this study perceived that their back condition might be viewed negatively by others in the workplace. Other studies have reported on the stigma associated with low back pain, for example that having time off work with a bad back has acquired 'moral stigma' because of media reports associating it with fraudulent benefit claims [18]; those with the condition may perceive that their condition will be doubted by employers and colleagues [12]. There seemed to be a desire for participants to explain their symptoms, and a desire for clinicians to diagnose and investigate. The term 'non-specific low back pain was not used by any of the participants. It was common for the participants to have seen several clinicians about their back pain, in some cases over several years. As Sawney and Challenor report [28], patients are inclined to believe the first diagnosis they are given and labels then become difficult to remove. Many participants perceived that a history of physical work, and increasing age were associated risk factors, although in reality there is little evidence to support these beliefs [29].

The participants in this study did not feel reassured by, or fully informed about their condition by the explanations they had received from clinicians. As Holloway argues [18] the 'paradigm shift' in the treatment model for low back pain to self-management, rather than cure, is relatively recent, and patients (and their employers) may not understand it. The results of our study show that the message that back pain is normal and self-manageable is either not being given by clinicians or not being heard by patients. Those who have received biomedical explanations and specific diagnoses in the past are likely to be particularly confused and in greater need of advice explaining the nature of 'chronic' pain and the role of heavy physical work and age in back pain. The latter is particularly important as the age of retirement increases in line with life expectancy [30]; there is little research published on back pain and the ageing worker, and studies indicate that quality of work life impacts on quality of life in retirement. Unless clinicians are able and willing to explain the changing nature of back pain management to employers, it remains with the patient to interpret the information and advice given by clinicians.

Although medication is a key evidence-based tool in symptom management in low back pain [21-23], the participants in this study expressed uncertainties about their medication, including its effect on their ability to work. In 
comparison with other studies of primary care back pain management (which have for example examined the advice given by GPs to patients about activity including work) there have been few studies of how the subject of medication is approached within the consultation. A review by Broekmans et al. [31] has concluded that medication adherence is poor in patients with chronic pain and a further study [32] has also shown that dissatisfaction with medication is common in this client group. Banbury et al. [33] argue the need for healthcare professionals, particularly GPs and pharmacists to aim for greater concordance when prescribing medication for back pain. Their study demonstrated that patients with low back pain had little knowledge about how to take medication, perceived it as ineffective, were worried about side-effects, and concerned about masking of symptoms, and possible addiction. In addition, McCracken et al. [34] demonstrated that perceptions of others' negative attitudes toward the use of analgesia can affect patients' adherence. Some studies have indicated that effective medication can increase productivity in chronic health conditions [35], but the use of opioids, particularly 'strong' opioids has been associated with work loss in low back pain [36]. However, there is very little research published on the role of weaker medications in vocational rehabilitation for low back pain. Attitudes towards medication, and its use in work retention for back pain would seem to be an area that needs to be addressed.

Hansson [37] and Hooftman [38] have suggested that the decision to report sick is not taken lightly by employees with back pain. In our study most of the participants were reluctant to take sick leave, not only because of their concerns about negative attitudes to back pain, but also due to absence management policies that appear punitive to those with chronic, fluctuating conditions, particularly those who take short term absences. They therefore seem to be doubly disadvantaged and problems may then become hidden from the employer. There is some evidence that 'presenteeism' (attending work whilst feeling unwell) for chronic conditions including back pain may be increasing as a result of rigid absence policies [39]. Although its effect on productivity is difficult to establish, it has been argued that presenteeism may have a detrimental effect on future health [40]. The economic costs of this may be considerable. For example, in a recent report, the costs of presenteeism for mental health problems were estimated at $£ 605$ per employee annually [41]. A large number of employers use absence records when selecting for redundancy and appointing new staff, and this is naturally of great concern to the individual employee. The Chartered Institute of Personnel and Development [8] advises employers to be aware that they should monitor employees' performance and behaviour, not just their attendance levels, for indications that they might be unwell, particularly in the current economic climate when greater job insecurity due to the recession may be responsible for reduced sickness absence. However, employers also need to be aware of the reasons why workers with low back pain may be reluctant to disclose their condition, and provide greater opportunities for supporting openness. There is a level of stigma associated with back pain, whether real or perceived [18]. This may result in workers with back pain feeling fraudulent when they feel they cannot perform their usual work tasks whilst able to carry out basic daily living activities. This fear of being perceived as a 'cheat' can compound the anxieties of coping with the condition itself [42].

\section{Strengths and Limitations}

Qualitative studies should have credibility, dependability and transferability [43]. In this study, information was collected using semi-structured interviews based on previous research findings which provided a theoretical basis and so greater credibility to the topic guide. Individual interviews were chosen to encourage each participant in sharing their individual experiences and perceptions without being influenced by the presence and views of other participants which might have arisen in a focus group setting [44].

Dependability was increased by having the same interviewer who transcribed the interviews verbatim (CC). Interview transcriptions and suggested themes were repeatedly checked, compared and revised with one of the co-authors (PJW) in order to increase credibility and dependability. It may be considered a weakness of the study that these themes were not confirmed by the participants; however, they would not have had the same access to the literature, or other interview transcriptions. Bias could have arisen because the interviewer had recently been working as a clinician with the back pain rehabilitation team. It was possible that she might be identified as a clinician rather than a researcher by the recruiting clinicians, by herself and thus by the participants. This may have influenced their contribution to the interview as they may have wanted to convince the researcher of the legitimacy of their illness story; a 'moral plot' [45]. To minimise these issues, the researcher requested that any questions about back pain were dealt with after the interview had been completed.

Convenience sampling was chosen for this study because of restricted time and resources, but the findings may be considered less transferable as a result. However, transferability was facilitated by providing: a detailed description of the method of selection; the process of analysis; the characteristics of the participants (without revealing their identities), and by the inclusion of 
appropriate quotations. There were fewer participants recruited who were employed by small enterprises $(<50$ employees) compared with those who worked for large employers ( $>250$ employees). The reason for this is unclear. It may be that the participants were representative of the UK economy: recent statistics show that whilst small enterprises $(<50$ employees) account for more than $99 \%$ of businesses, large employers (public and private) account for almost $60 \%$ of the workforce [46]. However, it might also be that the pressures of working for a small employer impose actual or perceived obstacles to accessing healthcare, or taking part in a research study.

\section{Conclusion}

The participants in this study had been able to remain in employment with low back pain, but concerns about their work ability remained, despite the healthcare interventions they had received. In particular, they had not been reassured as to the benign nature of persistent and recurrent low back pain and its relationship with work tasks. Neither had their concerns about analgesia been allayed. Participants felt uncomfortable about disclosing their health condition at work, and worried about the implications of employers' absence management policies. We conclude that specific attention to these factors should be made by clinicians and employers as this might enable people to work more confidently with low back pain.

Acknowledgments The patients who participated; the Nottingham Back and Pain Team who recruited the patients; Arthritis Research UK who funded the study (Primary Care Fellowship Grant ref. 17891); members of the steering group who contributed to the study (Ms Janet Clifford, Dr Alison Hammond, Mr George Morris, Dr Tracey Sach).

Open Access This article is distributed under the terms of the Creative Commons Attribution Noncommercial License which permits any noncommercial use, distribution, and reproduction in any medium, provided the original author(s) and source are credited.

\section{References}

1. Schonstein E, Kenny DT, Keating J, Koes BW. Work conditioning, work hardening and functional restoration for workers with back and neck pain. Cochrane Database Syst Rev. 2003;(1): CD001822.

2. Williams RM, Westmorland MG, Lin CA, Schmuck G, Creen M. Effectiveness of workplace rehabilitation interventions in the treatment of work-related low back pain: a systematic review. Disabil Rehabil. 2007;29:607-24.

3. Taimela S, Malmivaara A, Justen S, Laara E, Sintonen H, Tiekso $\mathrm{J}$, et al. The effectiveness of two occupational health intervention programmes in reducing sickness absence among employees at risk. Two randomised controlled trials. Occup Environ Med. 2008;65:236-41.

4. Kendall NAS, Burton AK, Main CJ, Watson PJ. Tackling musculoskeletal problems: a guide for clinic and workplace: identifying obstacles using the psychosocial flags framework. London: The Stationery Office; 2009.

5. Franche R-L, Cullen K, Clarke J, Irvin E, Sinclair S, Frank J. Workplace-based return-to-work interventions: a systematic review of the quantitative literature. J Occup Rehab. 2005;15: 607-31.

6. Kuoppala J, Lamminpaa A. Rehabilitation and work ability: a systematic literature review. J Rehab Med. 2008;40:796-804.

7. Improving health, work: changing lives. The Government's Response to Dame Carol Black's review of the health of Britain's working-age population. Presented to Parliament by the Secretaries of State of the Department for Work and Pensions and the Department of Health by Command of Her Majesty. London: The Stationery Office; 2008.

8. Chartered Institute of Personnel and Development. Absence Management: Annual Survey Report. 2009. http://cipd.co.uk. Accessed 20 Nov 2009.

9. Health and Safety Executive. Musculoskeletal Disorders Mainly Affecting the Back. Headline data from 2008/9 Self-reported Workrelated Illness Questionnaire Module included in the National Labour Force Survey. 2009. http://www.hse.gov.uk/statistics/causdis/ musculoskeletal/back.htm. Accessed 20 Nov 2009.

10. Shaw L, Segal R, Polatajko H, Harburn K. Understanding return to work behaviours: promoting the importance of individual perceptions in the study of return to work. Disabil Rehabil. 2002;24:185-95.

11. Shaw WS, Huang Y-H. Concerns and expectations about returning to work with low back pain: Identifying themes from focus groups and semi-structured interviews. Disabil Rehabil. 2005;27:1269-81.

12. Soeker MS, Wegner L, Pretorius B. I'm going back to work: back injured clients' perceptions and experiences of their worker roles. Work. 2008;30:161-70.

13. Raak R, Wahren LK. Health experiences and employment status in subjects with chronic back pain: a long-term perspective. Pain Manag Nurs. 2006;7:64-70.

14. Patel S, Greasley K, Watson PJ. Barriers to rehabilitation and return to work for unemployed chronic pain patients: a qualitative study. Eur J Pain. 2007;11:831-40.

15. Magnussen L, Nilsen S, Råheim M. Barriers against returning to work-as perceived by disability pensioners with back pain: a focus group based qualitative study. Disabil Rehabil. 2007;29: 191-7.

16. Braun V, Clarke V. Using thematic analysis in psychology. Qual Res Psych. 2006;3:77-101.

17. Tuckett AG. Applying thematic analysis theory to practice: a researcher's experience. Contemp Nurse. 2005;19:75-87.

18. Holloway I, Sofaer-Bennett B, Walker J. The stigmatisation of people with chronic back pain. Disabil Rehabil. 2007;29:1456-64.

19. Corbett M, Foster NE, Ong BN. Living with low back painStories of hope and despair. Soc Sci Med. 2007;65:1584-94.

20. Lillrank A. Back pain and the resolution of diagnostic uncertainty in illness narratives. Soc Sci Med. 2007;57:1045-54.

21. Airaksinen O, Brox JI, Cedraschi C, Hildebrandt J, KlaberMoffett J, Kovacs F, et al. European guidelines for the management of chronic nonspecific low back pain. Eur Spine J. 2006;15: S192-300.

22. Van Tulder M, Becker A, Bekkering T, Breen A, del Real MTG, Hutchinson A, et al. European guidelines for the management of acute nonspecific low back pain in primary care. Eur Spine J. 2006;15:S169-91. 
23. Clinical Guideline 88. Low back pain: early management of persisting non-specific low back pain. May 2009. National Collaborating Centre for Primary Care. National Institute for Health and Clinical Excellence. http://www.nice.org.uk/nicemedia/pdf/ CG88NICEGuideline.pdf.

24. H M Government. Disability Discrimination Act 2005 (Chapter 13). London: Her Majesty's Stationery Office.

25. Koes BW, van Tulder MW, Thomas S. Diagnosis and treatment of low back pain. Br Med J. 2006;332:1430-4.

26. Bishop A. The role of attitudes and beliefs of health care practitioners in the management of low back pain. PhD Thesis, University of Keele, 2008.

27. Kendall NAS, Linton SJ, Main CJ. Guide to assessing psychosocial yellow flags in acute low back pain risk factors for long term disability and work loss. Accident Rehabilitation and Compensation Insurance Corporation of New Zealand and the National Health Committee. Wellington, New Zealand, 1997. [New Zealand].

28. Sawney P, Challenor J. Poor communication between health professionals is a barrier to rehabilitation. Occup Med. 2003;53: 246-8.

29. Burton K, Waddell G. Risk factors for back pain. In: Waddell G, editor. The Back Pain Revolution. Edinburgh: Churchill Livingstone; 2004. p. 91-113.

30. Department for Work and Pensions. Security in Retirement: Towards a New Pensions System. CM6841. Presented to Parliament by the Secretary of State for Work and Pensions by Command of Her Majesty. May 2006. http://www.officialdocuments.gov.uk/document/cm68/6841/6841.pdf. Accessed 20 Nov 2009.

31. Broekmans S, Dobbels F, Milisen K, Morlion B, Vanderschueren S. Medication adherence in patients with chronic non-malignant pain: is there a problem? Eur J Pain. 2009;13:115-23.

32. Campbell C, Cramb G. 'Nobody likes a back bore'- exploring lay perspectives of chronic pain: revealing the hidden voices of nonservice users. Scand J Caring Sci. 2008;22:383-90.

33. Banbury P, Feenan K, Allcock N. Experiences of analgesic use in patients with low back pain. Br J Nurs. 2008;17:1215-8.
34. McCracken LM, Hoskins J, Eccleston C. Concerns about medication and medication use in chronic pain. J Pain. 2006;7:726-34.

35. Goldfarb N, Weston C, Hartmann CW, Sikirika M, Crawford A, Hope HE, et al. Impact of appropriate pharmaceutical therapy for chronic conditions on direct medical costs and workplace productivity: a review of the literature. Dis Manage. 2004;7(1):61-75.

36. Volinn E, Fargo JD, Fine PG. Opioid therapy for nonspecific low back pain and the outcome of chronic work loss. Pain. 2009;142: 194-201.

37. Hansson H, Bostrom C, Harms-Ringdahl K. Sickness absence and sickness attendance-what people with neck or back pain think. Soc Sci Med. 2006;62:2183-95.

38. Hooftman WE, Westerman MJ, van der Beek AJ, Bongers PM, van Mechelen W. What makes men and women with musculoskeletal complaints decide they are too sick for work? Scand J Work Environ Health. 2008;34(2):107-12.

39. Munir F, Yarker J, Haslam C. Sickness absence management: Encouraging attendance or 'risk-taking' presenteeism in employees with chronic illness. Disabil Rehabil. 2008;30(19):1461-72.

40. Bergstrom G, Bodin L, Hagberg J, Lindh T, Aronsson G, Malin J. Does sickness presenteeism have an impact on future general health? Int Arch Occup Environ Health. 2009;82:1179-90.

41. Mental Health at Work: developing the business case. The Sainsbury Centre for Mental Health. 2007. Policy Paper 8. http://www.scmh. org.uk/pdfs/mental_health_at_work.pdf. Accessed 20 Nov 2009.

42. Lippel $\mathrm{K}$. The private policing of injured workers in Canada: legitimate management practices or human rights violations? Policy Practice Health Safety. 2003;1(2):97-117.

43. Graneheim UH, Lundman B. Qualitative content analysis in nursing research: concepts, procedures and measures to achieve trustworthiness. Nurse Educ Today. 2004;24:105-12.

44. Lehoux P, Poland B, Daudelin G. Focus group research and "the patient's view". Soc Sci Med. 2006;63:2091-104.

45. Werner A, Isaksen LW, Malterud K. 'I am not the kind of woman who complains of everything': illness stories on self and shame in women with chronic pain. Soc Sci Med. 2004;59:1035-45.

46. Department of Business Innovation and Skills. http://stats.berr. gov.uk/ed/sme/. Accessed 20 Nov 2009. 